\title{
Onset of Action and Efficacy of Ibuprofen Liquigel as Compared to Solid Tablets: A Systematic Review and Meta-Analysis
}

Hanan Al Lawati and Fakhreddin Jamali

Faculty of Pharmacy \& Pharmaceutical Sciences, University of Alberta, Edmonton, Alberta, Canada.

Received, April 18, 2016; Revised August 2, 2016; Accepted, August 15, 2016; Published, August 16, 2016.

\begin{abstract}
Purpose. Ibuprofen liquigel has been believed to provide faster analgesic effect. However, comparative studies evaluating the efficacy of liquigel versus regular tablets are not available. Hence, we carried out a systematic review and a meta-analysis to compare the onset of action and efficacy of over-the-counter doses of ibuprofen liquigel (IBU $\mathrm{LG}_{\mathrm{L}}$ ) vs ibuprofen tablets $\left(\mathrm{IBU}_{\mathrm{T}}\right)$. Methods. Published clinical trials of $\mathrm{IBU}_{\mathrm{LG}}$ and $\mathrm{IBU}_{\mathrm{T}}$ were identified through a systematic search of various data bases up to October, 2015. Results. In total 18 eligible studies on $\mathrm{IBU}_{\mathrm{T}}$ and 4 on $\mathrm{IBU}_{\mathrm{LG}}$ were found. There was no significant difference in the median time to the first perceptible pain relief or the proportion of patients with more than $50 \%$ pain relief between the two products. However, $\mathrm{IBU}_{\mathrm{LG}}$ yielded significantly greater odd ratios in meaningful pain relief at 60,90 and 120 min, but not at $30 \mathrm{~min}$, as compared with $\mathrm{IBU}_{\mathrm{T}}$. Conclusion. The available evidence, although not overwhelming, suggest a faster onset of analgesia for liquigel as compared with tablets.
\end{abstract}

This article is open to POST-PUBLICATION REVIEW. Registered readers (see "For Readers") may comment by clicking on ABSTRACT on the issue's contents page.

\section{INTRODUCTION}

Ibuprofen is a non-steroidal anti-inflammatory drug (NSAID) derivative of the propionic acid that is used throughout the world for relief of pain and inflammation in both acute and chronic conditions [1]. The favorable analgesic effect of ibuprofen, even at low over-the-counter (OTC) oral doses, has made this agent the gold standard against which many new agents are evaluated for efficacy [2].

The management of acute episodes of pain requires the use of analgesic agents that have the ability to get absorbed rapidly and efficiently to yield rapid onset of pain relief. Ibuprofen is a Biopharmaceutics Classification System (BCS) ([3]) class II drug with low solubility at $\mathrm{pH} 1.2$ and 4.5 but high solubility at $\mathrm{pH} 6.8$, and is very permeable through physiological membranes [4]. In fact, it is found to be completely absorbed allowing for almost total bioavailability. However, the onset of absorption greatly depends on the dissolution of the dosage form [5].

In recent years, various oral formulations and different salts of ibuprofen have been investigated for their absorption properties and for their speed of onset of action with the hope of providing a rapid rise in plasma concentrations and, hence, a fast analgesic effect. They include $\mathrm{S}(+)$ ibuprofen [6], ibuprofen lysine [7, 8], ibuprofen sodium [9], ibuprofen arginate [7, 10], and ibuprofen liquigel (Advil Liqui-Gels, Pfizer, NY, USA).

Ibuprofen liquigel is a soft gelatin capsule that is hermetically sealed and contains ibuprofen as free acid and potassium salt in a solubilised form [11]. This newer solid dosage form of ibuprofen has been reported to have a rapid rate of absorption in healthy volunteers [12]. While ibuprofen rate of absorption in patients in pain is not reported, it has been shown to be an effective analgesic with minor advantages in onset of action as compared with ketoprofen and acetaminophen $1000 \mathrm{mg}[13,14]$. However, results of clinical trials, if any, that compare liquigel with solid dosage forms of ibuprofen as an active comparator have not been reported, hence, any advantage of such formulations remains unproven. This is particularly important since, due to the popularity of ibuprofen liquigel, many other analgesics have become available on the market in the form of liquid gel. We, therefore, attempted to compare the onset of analgesia and efficacy of the liquigel with solid dosage forms of ibuprofen by

Corresponding Author: Fakhreddin Jamali, Faculty of Pharmacy \& Pharmaceutical Sciences, Katz Centre for Pharmacy \& Health Research, 11361 - 87 Avenue, Edmonton, Alberta, Canada T6G 2E1. 
undertaking a systematic review and meta-analysis of all the studies that report onset of analgesia and efficacy of ibuprofen after administration of these formulations for the treatment of dental pain or migraine or tension-type headache.

\section{METHOD}

Published reports of randomized controlled trials on ibuprofen tablets $\left(\mathrm{IBU}_{\mathrm{T}}\right)$ or liquigels $\left(\mathrm{IBU}_{\mathrm{LG}}\right)$ at any dose were identified through a systematic search of PubMed, Embase, Google Scholar and the Cochrane library from inception until October, 2015. Key words used in the search included: ibuprofen, onset, human, dental, oral surgery, migraine, and tensiontype headache. Moreover, the reference lists of the retrieved articles were scanned for relevant studies. The screening and eligibility assessment of the reports was carried out independently by the two authors. There was a lack of access to unpublished data, and so the review only included published reports. Moreover, conference abstracts, case reports, or clinical observations were found to lack the details required in the analysis, and thus were not included. No language restriction was imposed.

The review was restricted to clinical studies related to the use of ibuprofen as an analgesic for dental pain, tension-type headache, and migraine. Studies were included if they were randomized, double blind, and placebo controlled studies that evaluated a single dose of ibuprofen administered following a moderate to severe episode of pain associated with one of the above mentioned conditions. Multiple dose studies were included only if the relevant single-dose data were provided. Studies on the use of ibuprofen as a pre-emptive treatment were not included, nor were studies which only used other than the conventional marketed IBU or $\mathrm{IBU}_{\mathrm{LG}}$. Therefore, ibuprofen salt formulations marketed such as ibuprofen sodium or ibuprofen arginate were excluded from the review. The inclusion criteria also required the use of the double stopwatch method, a patient population aged at least 12 years, and monitoring the patients for three hours or more post-dose.

Relevant studies were categorised on the basis of whether the ibuprofen solid tablets or the ibuprofen liquigel were used. In instances where the results from the studies where only reported graphically, the relevant graphs were digitized using digitizeit (http://www.digitizeit.de, Germany) and the "grabit" function in MATLAB (MathWorks Inc., Natick MA,
USA), and the data were extracted. In particular, the Kaplan-Meier time to event curves were analysed by the approach suggested by Guyot et al [15].

Two measures of onset of pain relief were considered, namely, the time to the first perceptible pain relief (FPPR) and the meaningful pain relief (MPR), both of which are patient-reported outcome captured as part of the double stopwatch method [16]. Kaplan-Meier survival median times to the above events were averaged with the weights being proportional to both the sample sizes and inverse of the variance. The latter, however, was measurable only for the data reported in the studies that provided a measure of variance. Moreover, the outcome of achieving meaningful pain relief at $30,60,90$, and 120 min post-dose were calculated. The proportion of patients achieving MPR at the above specific times, and the relevant odd ratios (OR) against placebo were calculated. Setting $\mathrm{IBU}_{\mathrm{T}}$ as the reference $(\mathrm{OR}=1)$, the $\mathrm{OR}$ for $\mathrm{IBU}_{\mathrm{LG}}$ was also calculated by an adjusted indirect comparison [17]. Variation among studies was anticipated, and due to the heterogeneity of the pooled data the OR values for meaningful pain relief were estimated using the DerSimonial-Laird method [18]. Heterogeneity among the studies in reporting an outcome is detected using the Cochran-Q test and the percentage of variation across the different studies that is attributed to heterogeneity is quantified using the $\mathrm{I}^{2}$ inconsistency test.

As the measure of efficacy, we calculated the total pain relief score (TOTPAR) over $6 \mathrm{~h}$. Pain relief is measured throughout the study at specific time intervals on a 5-point categorical scale (0 (no relief), 1 (slight relief), 2 (moderate relief), 3 (good relief), 4 (complete relief)). TOTPAR, which is an integrated pain score representing a time-weighted measure of the total area under the pain relief curve, has a higher sensitivity than many other outcome measures such as the sum of pain intensity difference score [19]. We used the Student's t-distribution test to compare the calculated TOTPAR scores [20]. Moreover, we used verified linear regression equations to calculate the proportion of patients experiencing more than $50 \%$ pain relief as measured by TOTPAR, and calculated the relevant ORs against placebo and against each other [21].

\section{RESULTS}

The database search (Figure 1) resulted in 100 reports that evaluated ibuprofen treatment for dental 
pain or dental surgery, migraine, or headache, and 3 additional reports were identified from other resources.

Upon our preliminary screening, duplicate reports, only abstracts, case studies, reviews and observational studies were removed. Subsequently, the list was shortened to 64 reports. A further screening revealed that 12 of these reports did not use randomly controlled trials, and 10 did not include ibuprofen as an active comparator in the study; e.g., as a rescue medication. The remaining 42 full text articles were checked for eligibility. Among these, 4 studies were related to the use of ibuprofen as a preemptive treatment, 2 used ibuprofen lysine, 1 used extended-release ibuprofen, 1 used sodium ibuprofen and ibuprofen acid incorporating poloxamer, 8 did not include results of the double stopwatch method, 3 were not placebo-controlled studies, and 1 did not report placebo results. The remaining 22 studies (Table 1) met our inclusion criteria and were included in the review. These consisted of 18 studies that used $\mathrm{IBU}_{\mathrm{T}}$ and 4 that studied $\mathrm{IBU}_{\mathrm{LG}}$. Among the $\mathrm{IBU}_{\mathrm{T}}$ studies, 4 used Motrin IB (Motrin, McNeil Consumer Healthcare, Fort Washington PA, USA)

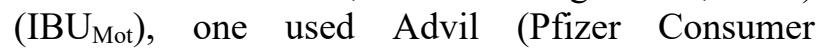
Healthcare, New York NY, USA), one had an arm for each of these two brands, one used Neurofen (Reckitt Benckiser, Slough, UK), while the rest either used unbranded ibuprofen tablets or did not specify the brand used.

\section{Identification}

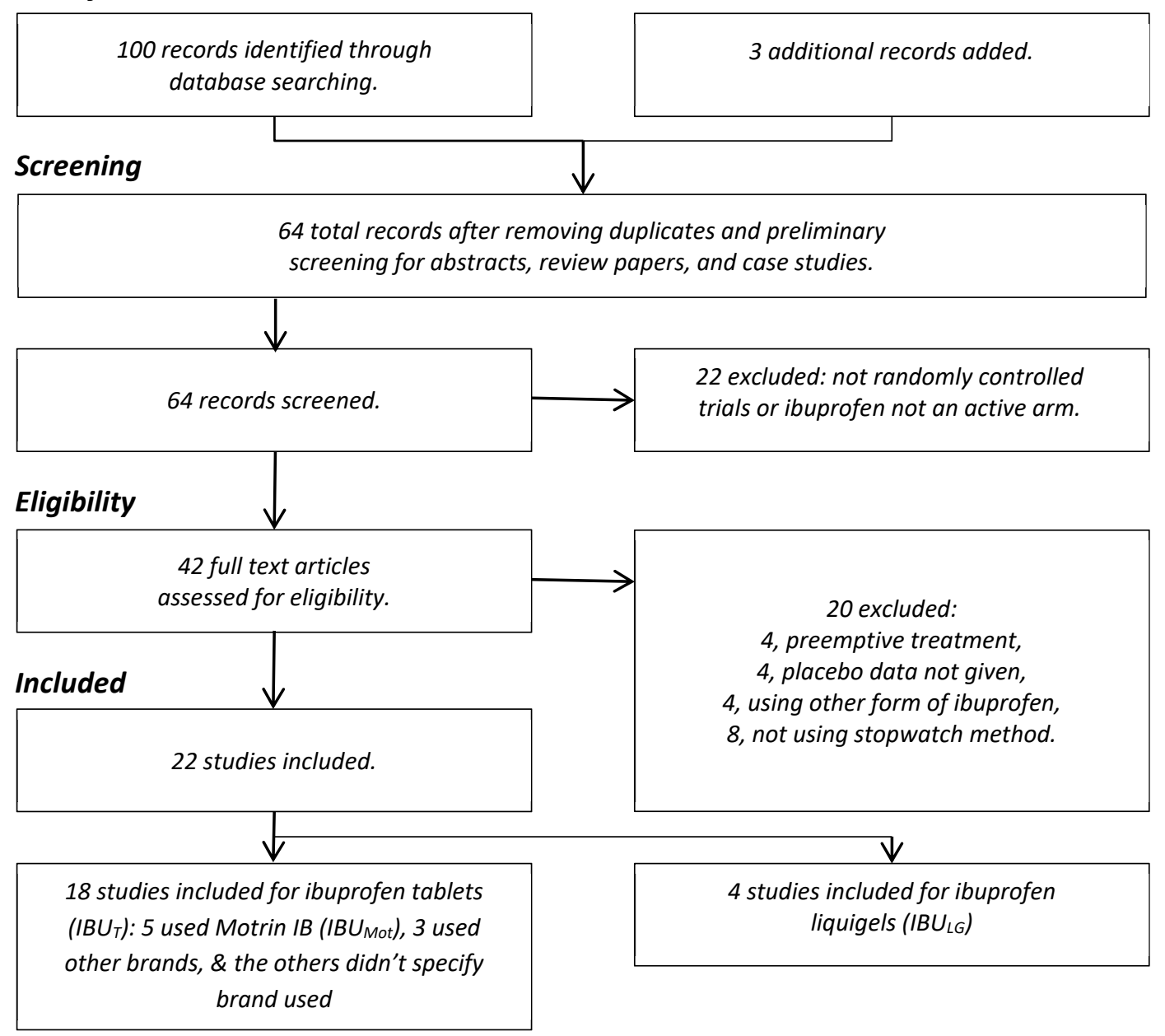

Figure 1. Flow of information in the systematic review 
Table 1. Ibuprofen studies included in the analysis

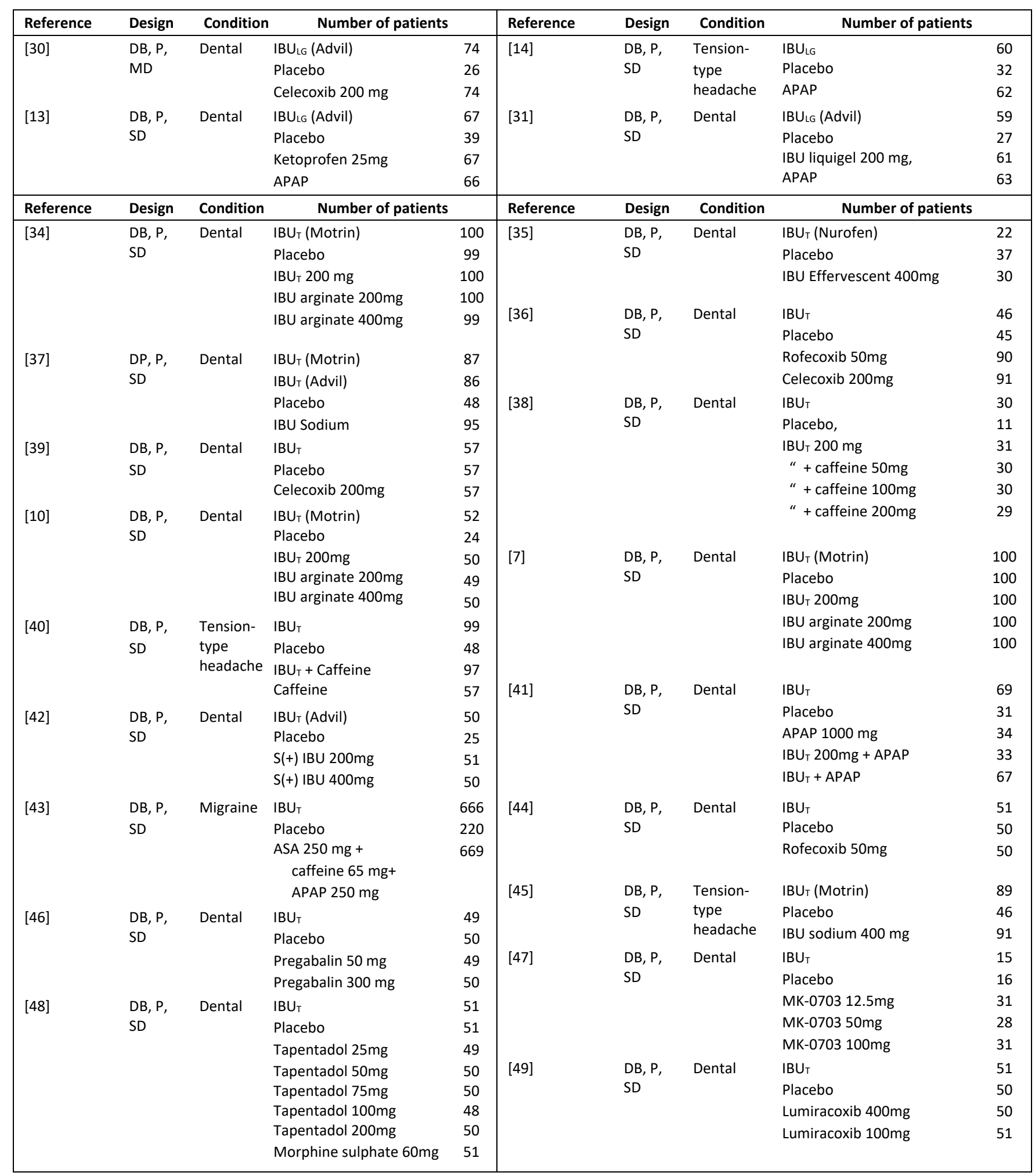

IBU: ibuprofen (dose is $400 \mathrm{mg}$ if not specified), APAP: acetaminophen (dose is $1000 \mathrm{mg}$ if not specified), ASA: aspirin $\mathrm{DB}$ : double-blind, $\mathrm{P}$ : placebo-controlled, SD: single-dose, MD: multiple-dose. 


\section{Confirmed first perceptible pain relief}

All of the studies included in the review measured pain relief over various times up to $12 \mathrm{~h}$. Moreover, all of the studies claimed to have used the double stopwatch method [16] but some did not report the data.

As a measure of onset of action, FPPR has been presented in 2 studies for $\mathrm{IBU}_{\mathrm{LG}}$ and in 16 studies for $\mathrm{IBU}_{\mathrm{T}}$ (Table 2). Moreover, both of the $\mathrm{IBU}_{\mathrm{LG}}$ studies and five of the $I_{T} U_{T}$ studies provided 95\% confidence interval for the median times. FPPR was achieved for $50 \%$ of patients significantly faster following both $I_{B} U_{T}$ and $I B U_{L G}$ as compared with placebo. However, the difference between the two formulations was not significant.

\section{Confirmed meaningful pain relief}

The MPR values were reported in all 4 of the $I_{B} U_{L G}$ studies and in 13 studies for $\operatorname{IBU}_{\mathrm{T}}$ (Table 3). Moreover, all of the $\mathrm{IBU}_{\mathrm{LG}}$ studies and 3 of the $\mathrm{IBU}_{\mathrm{T}}$ studies provided $95 \%$ confidence intervals for the median times. As depicted in Table $3,50 \%$ of the patients who used either $\mathrm{IBU}_{\mathrm{T}}$ or $\mathrm{IBU}_{\mathrm{LG}}$ recorded significantly faster MPR than those who took placebo. The median MPR was significantly shorter for $\mathrm{IBU}_{\mathrm{LG}}$ than for IBU $\mathrm{I}_{\mathrm{T}}$.

A great deal of variability is observed with the $\mathrm{IBU}_{\mathrm{T}}$ studies with median MPR ranging from 35 to $161 \mathrm{~min}$. Moreover, when the analysis is restricted to $\mathrm{IBU}_{\mathrm{Mot}}$ studies, the pooled median time from 5 studies which reported the outcome reduces from 138 to $52 \mathrm{~min}$ with sample-size weighing.

Another outcome measure considered, which complements the median times to MPR, is the proportion of patients achieving MPR at 30, 60, 90, and $120 \mathrm{~min}$ post-dose (Table 4). Three $\mathrm{IBU}_{\mathrm{LG}}$ articles provided such data and so did 4 of the $\mathrm{IBU}_{\mathrm{T}}$ reports. One additional $\mathrm{IBU}_{\mathrm{T}}$ study provided the data at all times except at 90 min post-dose, and one more provided the data at only 60 , and 120 min post-dose. Both treatments provided significantly greater OR than placebo at all measured times.

Table 2. Median times to the first perceptible pain relief (FPPR) for ibuprofen liquigel (IBU $\mathrm{LG}_{\mathrm{G}}$ ) and tablet $\left(\mathrm{IBU}_{\mathrm{T}}\right)$

\begin{tabular}{|c|c|c|c|c|c|}
\hline \multirow[b]{2}{*}{ Reference } & $\mathrm{IBU}_{\mathrm{LG}} 400 \mathrm{mg}$ & Placebo & \multirow[b]{2}{*}{ Reference } & \multirow{2}{*}{$\begin{array}{c}\mathrm{IBU}_{\mathrm{T}} 400 \mathrm{mg} \\
\begin{array}{c}\text { Median time, } \mathrm{min} \\
(95 \% \mathrm{Cl})^{\mathrm{a}}\end{array}\end{array}$} & \multirow{2}{*}{$\begin{array}{c}\text { Placebo } \\
\text { Median time, } \min \\
(95 \% \mathrm{Cl})^{\mathrm{a}}\end{array}$} \\
\hline & $\begin{array}{c}\text { Median time, } \min \\
(95 \% \mathrm{Cl})^{\mathrm{a}}\end{array}$ & $\begin{array}{l}\text { Median time, } \min \\
(95 \% \mathrm{Cl})^{\mathrm{a}}\end{array}$ & & & \\
\hline [14] & $39.0(36.2-41.5)$ & 113.0 & {$[39]^{\mathrm{c}}$} & $24.0(21.0-28.0)$ & 38.0 \\
\hline \multirow[t]{3}{*}[31]{} & \multirow[t]{3}{*}{$10.2(9.0-13.8)$} & \multirow[t]{3}{*}{$>180$} & {$[46]^{\mathrm{c}}$} & $16.0(10.2-20.5)$ & $>180$ \\
\hline & & & {$[35]^{\mathrm{c}}$} & $30.6(13.2-69.0)$ & 24.6 \\
\hline & & & {$[36]^{\mathrm{c}}$} & $24.0(24.0-42.0)$ & $>180$ \\
\hline \multicolumn{2}{|c|}{ Pooled (weighted by sample size) } & & {$[49]^{\mathrm{c}}$} & $41.5(29.5$ - 59.0) & $>180$ \\
\hline $\mathrm{IBU}_{\mathrm{LG}}$ & $24.7(22.7-27.8)$ & & {$[34]^{d}$} & 12.0 & 9.0 \\
\hline \multicolumn{2}{|c|}{ Pooled (inverse variance) } & & {$[37]^{b, d}$} & $25.8,25.1$ & $>180$ \\
\hline $\mathrm{IBU}_{\mathrm{LG}}$ & $23.0(21.1-26.1)$ & & {$[10]^{\mathrm{d}}$} & 14.0 & 14.0 \\
\hline & & & {$[40]$} & 69.0 & 88.0 \\
\hline & & & [48] & 48.0 & $>180$ \\
\hline & & & [38] & 14.0 & 14.0 \\
\hline & & & {$[7]^{d}$} & 16.0 & 97.5 \\
\hline & & & {$[41]$} & 48.6 & 21.0 \\
\hline & & & [44] & 48.0 & $>180$ \\
\hline & & & {$[45]^{d}$} & 43.6 & $>180$ \\
\hline & & & [47] & 60.0 & $>180$ \\
\hline & & & \multicolumn{2}{|c|}{ Pooled (weighted by sample size) } & \\
\hline & & & $\mathrm{IBU}_{\mathrm{T}}$ & 32.5 & \\
\hline & & & $\mid B U_{T}^{c}$ & $26.9(20.4-40.3)$ & \\
\hline & & & $\mathrm{IBU}_{\mathrm{MOT}^{\mathrm{d}}}$ & 22.6 & \\
\hline & & & \multicolumn{2}{|c|}{ Pooled (inverse variance) } & \\
\hline & & & $\mathrm{IBU}_{\mathrm{T}}^{\mathrm{c}}$ & $22.4(18.3-29.2)$ & \\
\hline
\end{tabular}

${ }^{a} 95 \%$ confidence interval when available; ${ }^{b}$ study had two arms of ibuprofen; ${ }^{\mathrm{c}}$ studies that reported $95 \% \mathrm{Cl}$; ${ }^{\mathrm{d}} \mathrm{Motrin}$ IB was used in the study. 
Table 3. Median times to meaningful pain relief (MPR) for ibuprofen liquigel (IBU $\mathrm{LG}_{\text {) }}$ and tablet (IBU $)$

\begin{tabular}{|c|c|c|c|c|c|}
\hline \multirow[b]{2}{*}{ Reference } & $\mathrm{IBU}_{\mathrm{LG}} 400 \mathrm{mg}$ & Placebo & \multirow[b]{2}{*}{ Reference } & \multirow{2}{*}{$\begin{array}{c}\mathrm{IBU}_{\mathrm{T}} 400 \mathrm{mg} \\
\begin{array}{c}\text { Median time, } \mathrm{min} \\
(95 \% \mathrm{Cl})^{\mathrm{a}}\end{array}\end{array}$} & \multirow{2}{*}{$\begin{array}{c}\text { Placebo } \\
\text { Median time, } \min \\
(95 \% \mathrm{Cl})^{\mathrm{a}}\end{array}$} \\
\hline & $\begin{array}{l}\text { Median time, } \min \\
(95 \% \mathrm{Cl})^{\mathrm{a}}\end{array}$ & $\begin{array}{l}\text { Median time, min } \\
(95 \% \mathrm{Cl})^{\mathrm{a}}\end{array}$ & & & \\
\hline$[30]$ & $46.3(42.4-61.1)$ & $>180$ & {$[39]^{\mathrm{c}}$} & $61.0(47.0-76.0)$ & $>180$ \\
\hline [13] & $24.2(21.1-25.4)$ & $>180$ & {$[43]^{\mathrm{c}}$} & $148(135-163)$ & $>180$ \\
\hline [14] & $39.0(36.8-41.6)$ & $>180$ & {$[35]^{\mathrm{c}}$} & $47.4(23.4-135)$ & $>180$ \\
\hline \multirow[t]{3}{*}{ [31] } & $28.8(26.4-33.0)$ & $>180$ & {$[34]^{d}$} & 44.0 & $>180$ \\
\hline & & & {$[37]^{b, d}$} & $60.7,52.0$ & $>180$ \\
\hline & & & {$[10]^{\mathrm{d}}$} & 48.0 & $>180$ \\
\hline \multicolumn{2}{|c|}{ Pooled (weighted by sample size) } & & [40] & 161 & $>180$ \\
\hline$I B U_{L G}$ & $35.0(32.0-41.0)$ & & [42] & 35.0 & $>180$ \\
\hline \multicolumn{2}{|c|}{ Pooled (inverse variance) } & & [48] & 48.0 & $>180$ \\
\hline $\mathrm{IBU}_{\mathrm{LG}}$ & $31.1(28.4-33.6)$ & & [38] & 52.0 & $>180$ \\
\hline & & & [41] & 124 & $>180$ \\
\hline & & & {$[7]^{d}$} & 58.0 & $>180$ \\
\hline & & & {$[45]^{\mathrm{d}}$} & 48.5 & $>180$ \\
\hline & & & \multicolumn{2}{|c|}{ Pooled (weighted by sample size) } & \\
\hline & & & $\mathrm{IBU}_{\mathrm{T}}$ & 104 & \\
\hline & & & $\mathrm{IBU}_{\mathrm{T}}^{\mathrm{c}}$ & $138(125-156)$ & \\
\hline & & & $\mathrm{IBU}_{\text {MOT }}{ }^{\mathrm{d}}$ & 52.0 & \\
\hline & & & \multicolumn{2}{|c|}{ Pooled (inverse variance) } & \\
\hline & & & $\mathrm{IBU}_{T}{ }^{\mathrm{c}}$ & $65.4(50.1-90.5)$ & \\
\hline
\end{tabular}

${ }^{a} 95 \%$ confidence interval when available; ${ }^{b}$ study had two arms of ibuprofen; ${ }^{\mathrm{c}}$ studies that reported $95 \% \mathrm{Cl}$; ${ }^{\mathrm{d}} \mathrm{Motrin} \mathrm{IB}$ was used in the study.

Table 4. Odd ratio and heterogeneity for the outcome of achieving meaningful relief at t=30, 60, 90, 120 min

\begin{tabular}{|c|c|c|c|}
\hline Groups & Random Effect OR $(95 \% \mathrm{Cl})$ & Cochran-Q & $\mathrm{I}^{2}$ (inconsistency) \\
\hline \multicolumn{4}{|l|}{$\mathrm{T}=\mathbf{3 0} \mathrm{min}$} \\
\hline $\mathrm{IBU}_{\mathrm{T}}$ vs Placebo & $1.89(1.24-2.86)$ & n.s. & n.s. \\
\hline $\mathrm{IBU}_{\mathrm{LG}}$ Vs Placebo & $5.90(1.91-19.0)$ & n.s. & n.s. \\
\hline$I B U_{L G}$ VS IBU ${ }_{T}^{a}$ & $3.14(0.91-10.8)$ & & \\
\hline \multicolumn{4}{|l|}{$T=60 \mathrm{~min}$} \\
\hline $\mathrm{IBU}_{\mathrm{T}}$ vs Placebo & $2.76(1.58-4.82)$ & 18.5 & $72.9 \%$ \\
\hline $\mathrm{IBU}_{\mathrm{LG}}$ Vs Placebo & $31.9(14.6$ - 69.7) & n.s. & n.s. \\
\hline$I B U_{L G}$ vs IBU $T^{a}$ & $11.6(4.4-30.2)$ & & \\
\hline \multicolumn{4}{|l|}{$\mathrm{T}=90 \mathrm{~min}$} \\
\hline $\mathrm{IBU}_{\mathrm{T}} \mathrm{Vs}$ Placebo & $2.85(1.36-6.00)$ & 19.1 & $84.3 \%$ \\
\hline $\mathrm{IBU}_{\mathrm{LG}}$ vs Placebo & $55.8(24.2-129)$ & n.s. & n.s. \\
\hline$I B U_{L G}$ Vs IBU $T^{a}$ & $9.61(6.39-60.1)$ & & \\
\hline \multicolumn{4}{|l|}{$T=120 \min$} \\
\hline $\mathrm{IBU}_{\mathrm{T}}$ vs Placebo & $3.67(1.79-7.53)$ & 39.1 & $87.2 \%$ \\
\hline $\mathrm{IBU}_{\mathrm{LG}}$ Vs Placebo & $35.1(16.5$ - 74.7) & n.s. & n.s. \\
\hline$I B U_{L G}$ VS IBU $T^{a}$ & $9.56(3.37-27.1)$ & & \\
\hline
\end{tabular}

Pooled data are based on 3 studies for $I B U_{L G}[13,14,30]$, and on 4 studies for $I B U_{T}$ at $t=90$ min $[7,10,34,43]$, on 5 studies at $t=30$ $\min (+[45])$, and on 6 studies at $t=60,120 \mathrm{~min}$ (+ [40]); n.s.: values are not significant at the $\alpha=0.05$ level; ${ }^{a}$ odd ratios of the adjusted indirect comparison. 
The differences between the products was not significant at $30 \mathrm{~min}$ post-dose, but became significant in favour of $I_{B} U_{L G}$ for all subsequent times.

Significant level of heterogeneity is observed in the outcome of time to reach MPR with the $\mathrm{IBU}_{\mathrm{T}}$ data at all times, with the exception of $30 \mathrm{~min}$ post dose. At $2 \mathrm{~h}$ post dose, for example, the Cochran-Q test significantly indicates that there is no single value for time to MPR that the different $\mathrm{IBU}_{\mathrm{T}}$ studies are evaluating, while the $\mathrm{I}^{2}$ value suggests that over $87 \%$ of the total variation across studies is due to heterogeneity rather than chance. No publication bias was detected by the Egger test except for the OR of $\mathrm{IBU}_{\mathrm{T}}$ against placebo at $2 \mathrm{~h}$ post-dose (data not reported).

Total pain relief and proportion of patients achieving at least $50 \%$ pain relief

Both $I B U_{T}$ and $I_{B U} U_{L G}$ were significantly more effective in relieving pain as measured by TOTPAR $(0-6 \mathrm{~h})$ than placebo. The mean pooled TOTPAR score for $\mathrm{IBU}_{\mathrm{T}}$ was 13.5 ( $\mathrm{n}=661,8$ studies) and 14.9 (95\% CI: $14.2,15.7, \mathrm{n}=379,4$ studies) for data that did not report variance and those that did, respectively. This value was 17.0 for $\operatorname{IBU}_{\mathrm{LG}}(95 \%$ CI: 16.0, 18.0, $\mathrm{n}=126,2$ studies) (Table 5). An independent Student's t-test [20] reveals that IBU $_{\mathrm{LG}}$ provided better pain relief as measured by TOTPAR (0-6 h) than that achieved with IBU $_{\mathrm{T}}$, although, with a small effect size (two-tailed t-test, $\mathrm{t}(503)=2.9$, $\mathrm{p}=0.0042$, Cohen's $\mathrm{d}=0.29$ ).

The available data allowed calculation of proportion of patients with more than $50 \%$ pain relief for $2 \mathrm{IBU}_{\mathrm{LG}}$ and $8 \mathrm{IBU}_{\mathrm{T}}$ studies (a total of 9 included $\mathrm{IBU}_{\mathrm{T}}$ groups) (Table 6). Significantly more patients achieved at least $50 \%$ total pain relief over $6 \mathrm{~h}$ of dosing with either of $I_{B} U_{T}$ or IBU $_{L G}$ than with placebo, showing an odd ratio of 11.7 (95\% CI: 5.20 , 26.4) with $\mathrm{IBU}_{\mathrm{T}}$ and 25.9 (95\% CI: 11.4, 58.7) with $\mathrm{IBU}_{\mathrm{LG}}$ against placebo. No significant difference was observed between the two products when compared to each other. The Cochran-Q test indicates the presence of heterogeneity in the $\mathrm{IBU}_{\mathrm{T}}$ studies with regards to this outcome and the $\mathrm{I}^{2}$ inconsistency tests attributes over $80 \%$ of the variation in the results to the heterogeneity or other forms of bias rather than chance.

Table 5. Total pain relief (TOTPAR) score over 0-6 $\mathrm{h}$

\begin{tabular}{|c|c|c|c|c|c|c|c|c|c|c|c|c|c|}
\hline \multirow{2}{*}{ Reference } & \multicolumn{3}{|c|}{$\mathrm{IBU}_{\mathrm{LG}} 400 \mathrm{mg}$} & \multicolumn{3}{|c|}{ Placebo } & \multirow{2}{*}{ Reference } & \multicolumn{3}{|c|}{$\mathrm{IBU}_{\mathrm{T}} 400 \mathrm{mg}$} & \multicolumn{3}{|c|}{ Placebo } \\
\hline & $\mathbf{N}$ & Mean & SD & $\mathbf{N}$ & Mean & SD & & $\mathbf{N}$ & Mean & $S D^{a}$ & $\mathbf{N}$ & Mean & $S D^{a}$ \\
\hline [13] & 67 & 17.4 & 5.7 & 39 & 4.33 & 7.3 & {$[39]^{c}$} & 57 & 14.9 & 6.2 & 57 & 3.70 & 5.7 \\
\hline \multirow[t]{2}{*}{ [31] } & 59 & 16.6 & 5.8 & 27 & 5.25 & 7.7 & {$[40]^{\mathrm{c}}$} & 99 & 13.3 & 9.6 & 48 & 11.4 & 9.2 \\
\hline & & & & & & & {$[42]^{\mathrm{c}}$} & 50 & 11.5 & 6.9 & 25 & 3.45 & 5.9 \\
\hline \multirow[t]{9}{*}{ Pooled $^{e}$} & 126 & 17.0 & 5.7 & 66 & 4.71 & 7.4 & {$[37]^{b, c, d}$} & 87 & 16.6 & 6.6 & 48 & 4.44 & 6.7 \\
\hline & & & & & & & {$[37]^{b, c}$} & 86 & 17.2 & 4.9 & & & \\
\hline & & & & & & & {$[34]^{d}$} & 100 & 14.9 & & 98 & 6.90 & \\
\hline & & & & & & & {$[10]^{\mathrm{d}}$} & 52 & 7.30 & & 24 & 1.70 & \\
\hline & & & & & & & [38] & 30 & 5.50 & & 11 & 0.00 & \\
\hline & & & & & & & {$[7]^{d}$} & 100 & 12.4 & & 100 & 4.51 & \\
\hline & & & & & & & Pooled & 661 & 13.5 & & 411 & 5.41 & \\
\hline & & & & & & & Pooled $^{c}$ & 379 & 14.9 & 7.4 & 178 & 5.94 & 7.8 \\
\hline & & & & & & & Pooled $^{d}$ & 339 & 13.4 & & 270 & 5.11 & \\
\hline
\end{tabular}

${ }^{a}$ Standard deviation (SD) when available; ${ }^{b}$ study had two arms of ibuprofen; ${ }^{c}$ studies which reported SD; ${ }^{d}$ studies which used Motrin IB; ${ }^{e}$ significant difference (two-tailed Student's t-test, $t(503)=2.88, p=0.0042$, Cohen's $d=0.29$ )

Table 6. Odd ratios and heterogeneity for the outcome of achieving more than $50 \%$ pain relief

\begin{tabular}{|cccc|}
\hline Groups & Random Effect OR (95\% Cl) & Cochran-Q & $\mathbf{I}^{\mathbf{2}}$ (inconsistency) \\
\hline $\mathrm{IBU}_{\mathrm{T}}$ vs Placebo & $11.7(5.15-26.4)$ & 41.9 & $80.9 \%$ \\
$\mathrm{IBU}_{\mathrm{LG}}$ vs Placebo & $25.9(11.4-58.7)$ & n.s. & n.s. \\
$\mathrm{IBU}_{\mathrm{LG}}$ VS IBU ${ }_{\mathrm{T}}{ }^{a}$ & $2.22(0.69-7.06)$ & & \\
\hline
\end{tabular}

Pooled data are based on two studies for $\operatorname{IBU}_{\mathrm{LG}}[13,31]$, and on eight studies for $I B U_{T}[7,10,34,37-40,42]$; n.s.: values are not significant at the $\alpha=0.05$ level; ${ }^{a}$ odd ratios of the adjusted indirect comparison. 


\section{DISCUSSION}

The task of developing an analgesic medication with a meaningful onset of action has proven to be difficult if not impossible [22, 23]. This has been attributed to the gastric dysfunction that is associated with pain or the trauma of pain $[22,24]$. Reports [22, $25,26]$, except for one [27] suggest a reasonable correlation between analgesics concentration in the circulation and relief of pain. For an analgesic to act, however, the formulation has to disintegrate and dissolve before the active ingredient become available for absorption through the gastrointestinal (GI) tract. Although, depending on the drug $\mathrm{pKa}$, the process may commence in the stomach, the main site of absorption is the intestine. In the meantime, pain and/or its trauma causes gastric dysfunction; i.e., reduced gastric motility, a slow-down of gastric emptying and reduced fluid excretion that result in slow disintegration and subsequent dissolution in the stomach [22]. Various commercially available formulations, e.g., dissolved drug in soft gelatin capsules are claimed to have rapid GI absorption, hence, quick onset of action [13]. However, clinical evidence suggestive of accelerated onset of action of products containing the same active ingredient is nonexistent or not published. Recently, a more rapid absorption during episodes of pain has been reported for formulations that are not coated and contain some disintegration action, hence, their disintegration and dissolution are less dependent on the gastric function [24]. Similarly, accelerated onset of action has been reported for products with undisclosed formulations that contain various salts of ibuprofen [28, 29]. However, such data generated by studying patients in pain are not publicly available for soft gelatin capsules. IBU $\mathrm{LL}_{\mathrm{LG}}$ has been compared with various other drugs for the management of pain associated with migraine, headache, or dental procedures including celecoxib [30], acetaminophen [13, 14, 31 , and ketoprofen [13], but not with the other more solid formulations of ibuprofen. In the absence of comparative clinical studies, systematic reviews and indirect meta-analysis comparisons remain to be effective means of appraising clinical evidence.

Regarding a desirable onset of action, our analysis of the available data suggests, for the first time, a few advantages of liquigel over other available forms of ibuprofen. While the differences between products in FPPR were not significant (Table 2), IBU $\mathrm{LG}_{\mathrm{Li}}$ yielded a significantly faster MPR (Table 3). Similarly, when IBU LG was compared with $\mathrm{IBU}_{\mathrm{T}}(\mathrm{OR}=1)$, the $\mathrm{OR}$ for MPR was greater than unity (9.61 to 19.6 ) during $60-120 \mathrm{~min}$ assessment period. However, at $30 \mathrm{~min}$ this value was not significantly elevated for $\operatorname{IBU}_{\mathrm{LG}}(3.1 ; 95 \% \mathrm{CI}: 0.90$, 10.8). It is, therefore, reasonable to suggest that the liquigel exhibits a faster onset of pain relief than the other products. However, a clear difference between the products appears only at $60 \mathrm{~min}$.

In healthy subjects, plasma ibuprofen concentration peaks much faster following oral administration of $\operatorname{IBU}_{\mathrm{LG}}\left(T_{\max }, 30 \mathrm{~min},[12]\right)$ than other examined products $\left(T_{\max }, 2 \mathrm{~h},[32]\right)$. Ignoring the pathophysiological changes in response to pain [22], such a difference in the rate of absorption is expected to result in a significantly faster onset of analgesia for $I_{B U_{L G}}$ as compared with $I_{B} U_{T}$. However, our analysis suggests that a significantly greater response is only seen after $60 \mathrm{~min}$ rather than $30 \mathrm{~min}$. This delay may be attributed to the paininduced gastric dysfunction. In addition, Jones et al [27] who correlated ibuprofen plasma concentration with its analgesic effect following administration of a soluble form of the drug found no significant link between the two variables despite their $T_{\max }$ of 30 min. Therefore, the main reasons for the delay in analgesia following oral doses appear to include i) the pain-induced gastric dysfunction, hence, delayed absorption and ii) a gap between early rise in the drug plasma concentration and its arrival at the site of action. When administered in the form of solution, ibuprofen appears to be absorbed quickly independent of gastric dysfunction as $T_{\max }$ values of 25 and 30 min have been reported for both healthy subjects [32] and patients in pain [27], respectively. This is because the drug is available for absorption without the delays caused by disintegration of tablets or opening of capsule shell and subsequent dissolution of the active ingredient. Based on our analysis, it is reasonable to suggest that during episodes of pain, although both IBU $_{L G}$ and IBU $_{T}$ are subject to delayed absorption due to the reported gastric dysfunction, the former provides a faster relief of pain relative to the latter.

In typical clinical trials of analgesics small populations of patients are employed (50-100 patients/study arm, Table 1). Considering the inherent inter-subject variability in such studies, much larger population size is needed for reliable results. By pooling the available clinical trial data that have tested the products of interest, as we have done herein, the data may be analyzed with more statistical power. 
While approaches are often adopted to minimize bias in systematic reviews some sources of bias and heterogeneity that are inherent in the studies still exist [33]. In the eligible reports used in this analysis, the brand used is identified in 3 of the 4 $I_{B U}$ and only 7 out of 18 IBU $_{T}$ studies. This may ignore the potential between-products variability. For example, in our included reports we had 5 sets of data that identified Motrin IB (Motrin, McNeil Consumer Healthcare, Fort Washington PA, USA) as the brand. We found a shorter time to attain MPR (52.0 $\mathrm{min}$ ) as compared to the pooled data (104.1 $\mathrm{min})$ but still longer than that for $\operatorname{IB}_{\mathrm{LG}}(35.0 \mathrm{~min})$ (Table 3). Similarly, shorter FPPR values were observed for Motrin than that for the pooled $\mathrm{IBU}_{\mathrm{T}}$ so that it rendered the difference between Motrin and $I_{B U}$ insignificant (Table 2).

In our analysis we included all data available generated from patients with all acute type of pain (Table 1). However, the majority of the reports had included dental pain. When we analysed the available data on the dental pain only, we noticed very similar results except for FPPR that indicated a significant difference between IBU $_{\mathrm{LG}}$ (10.2 min; 95\% CI: 9.0, 13.8) and $\mathrm{IBU}_{\mathrm{T}}(26.9 \mathrm{~min} ; 95 \% \mathrm{CI}$ : 20.4, 40.3). However, this difference was based on only one study for IBU $\mathrm{LG}_{\text {that }}$ reported FPPR for dental pain.

To measure efficacy, we considered total pain relief score (TOTPAR) over $6 \mathrm{~h}$, which is an outcome measure that is commonly used in clinical trials of analgesia. It is based on summing a categorical pain relief scores (ranging from 0 to 4 ) for all participants at various time intervals after dosing. The results (Table 5) suggest that $I_{B} U_{L G}$ provides a significantly higher TOTPAR as compared with $\mathrm{IBU}_{\mathrm{T}}$, but the size of this effect is small (Cohen's $d=0.29$ ). Another outcome measured that is useful in determining the effectiveness of pain relieving agents is the proportion of patients with more than $50 \%$ pain relief (based on TOTPAR). This outcome can be computed according to a linear regression fit that has been developed by Moore et al [21] to dichotomize the data. The pooled odd ratio for this outcome did not indicate a significant difference between $\mathrm{IBU}_{\mathrm{LG}}$ and $I_{T}$, which suggest that the overall efficacy across the $6 \mathrm{~h}$ post-dose was comparable for both products.

\section{CONCLUSION}

The meta-analysis of the available clinical data suggests that both solid tablets and liquigel of ibuprofen are effective in controlling moderate to severe episodes of pain. The evidence, although not overwhelming, suggest a faster onset of analgesia for liquigel as compared with tablets. This information is timely in light of the ever increasing number of products in soft gelatin capsules appearing on the market. Well-powered comparative clinical trials are needed in this field.

\section{ACKNOWLEDEGMENTS AND CONFLICTS}

This research was supported by a University of Alberta Self-Directed grant. H.A. was a recipient of a scholarship granted by the government of Oman. Authors have no conflict of interest regarding the contents of the paper.

\section{REFERENCES}

1. Rainsford, K., History and development of ibuprofen, in Ibuprofen: Discovery, Development and Therapeutics. 2015, Wiley Blackwell: West Sussex UK. p. 1-21.

2. Sharav , Y. and R. Beoliel, Orofacial pain \& headache. 2008, Philadelphia: Elsevier Health Sciences.

3. Emami, J., In vitro-in vivo correlation: from theory to applications. J Pharm Pharm Sci, 2006. 9(2): p. 169-189.

4. Alvarez, C., et al., Investigation on the possibility of biowaivers for ibuprofen. J Pharm Sci., 2011. 100(6): p. 2343-9.

5. Klueglich, M., et al., Ibuprofen extrudate, a novel, rapidly dissolving ibuprofen formulation: relative bioavailability compared to ibuprofen lysinate and regular ibuprofen, and food effect on all formulations. J Clin Pharmacol, 2005. 45(9): p. 105561.

6. Evans, A.M., Comparative Pharmacology of $S(+)-$ Ibuprofen and (RS)-Ibuprofen. 2001: 20(1): 9-14. Clinical Rheumatology, 2001. 20(1): p. 9-14.

7. Mehlisch, D.R., A. Ardia, and T. Pallotta, A controlled comparative study of ibuprofen arginate versus conventional ibuprofen in the treatment of postoperative dental pain. J Clin Pharmacol, 2002. 42(8): p. 904-11.

8. Mehlisch, D.R., et al., Comparative study of ibuprofen lysine and acetaminophen in patients with postoperative dental pain. Clin Ther, 1995. 17(5): $\mathrm{p}$. 852-60. 
9. Jayawardena, S., R. Leyva, and D. Kellstein, Safety of a novel formulation of ibuprofen sodium compared with standard ibuprofen and placebo. Postgrad Med, 2015. 127(1): p. 33-7.

10. Desjardins, P., et al., Ibuprofen arginate provides effective relief from postoperative dental pain with a more rapid onset of action than ibuprofen. Eur J Clin Pharmacol, 2002. 58(6): p. 387-94.

11. Gullapalli, R.P., Soft gelatin capsules (softgels). J Pharm Sci, 2010. 99(10): p. 4107-48.

12. Anonymous, Compendium of Pharmaceuticals and Specialities. 2009, Ottawa, ON, Canada: Canadian Pharmacists Association.

13. Olson, N., et al., Onset of analgesia for liquigel ibuprofen $400 \mathrm{mg}$, acetaminophen $1000 \mathrm{mg}$, ketoprofen $25 \mathrm{mg}$, and placebo in the treatment of postoperative dental pain. . J Clin Pharmacol, 2001. 41(11): p. 1238-47.

14. Packman, B., et al., Solubilized ibuprofen: evaluation of onset, relief, and safety of a novel formulation in the treatment of episodic tension-type headache. Headache, 2000. 40: p. 561-7.

15. Guyot, P., et al., Enhanced secondary analysis of survival data: reconstructing the data from published Kaplan-Meier survival curves. BMC Med Res Methodol, 2012. 12(9): p. 1-13.

16. Laska, E.M., C. Siegel, and A. Sunshine, Onset and duration: measurement and analysis. Clinical Pharmacology \& Therapeutics, 1991. 49(1): p. 1-5.

17. Bucher, H.C., et al., The results of direct and indirect treatment comparisons in meta-analysis of randomized controlled trials. Journal of clinical epidemiology, 1997. 50(6): p. 683-691.

18. DerSimonian, R. and N. Laird, Meta-analysis in Clinical Trials. Controlled Clinical Trials, 1986. 7: p. 177-188.

19. Singh, N. and P. Chang, A systematic review of the sensitivity of efficacy endpoints TOTPAR and SPID in acute pain. The Journal of Pain, 2013. 14(4): p. S11.

20. Student, The probable error of a mean. Biometrika, 1908: p. 1-25.

21. Moore, A., H. McQuay, and D. Gavaghan, Deriving dichotomous outcome measures from continuous data in randomised controlled trials of analgesics: verification from independent data. Pain, 1997. 69: p. 127-30.

22. Jamali, F. and C.M. Kunz-Dober, Pain-mediated altered absorption and metabolism of ibuprofen: an explanation for decreased serum enantiomer concentration after dental surgery. $\mathrm{Br} \mathrm{J}$ Clin Pharmacol, 1999. 47: p. 391-6.

23. Almukainzi, M., et al., Disease specific modeling: Simulation of the pharmacokinetics of meloxicam and ibuprofen in disease state vs. healthy conditions. Eur J Pharm Biopharm, 2016. 100: p. 77-84.

24. Jamali, F. and A. Aghazadeh-Habashi, Rapidly dissolving formulations for quick absorption during pain episodes: ibuprofen. International Journal Of Clinical Pharmacology and Therapeutics, 2008. 46(2): p. 55-63.

25. Laska, E.M., et al., The correlation between blood levels of ibuprofen and clinical analgesic response. Clin Pharmacol Ther, 1986. 40: p. 1-7.

26. Seymour, R.A., P.J. Kelly, and J.E. Hawkesford, Pharmacokinetics and efficacy of low-dose ketoprofen in prospective dental pain. Clin Drug Invest, 1998. 15: p. 279-284.

27. Jones, K., R.A. Seymour, and J.E. Hawkesford, Are the pharmacokinetics of ibuprofen important determinants for the drug's efficacy in postoperative pain after third molar surgery? British Journal of Oral and Maxillofacial Surgery, 1997. 35(3): p. 173176.

28. Legg, T.J., et al., buprofen sodium is absorbed faster than standard Ibuprofen tablets: results of two openlabel, randomized, crossover pharmacokinetic studies. Drugs R D, 2014. 14(4): p. 283-290.

29. Lewis, D.W., et al., Children's ibuprofen suspension for the acute treatment of pediatric migraine. Headache: The Journal of Head and Face Pain, 2002. 42(8): p. 780-786.

30. Doyle, G., et al., Efficacy and tolerability of nonprescription ibuprofen versus celecoxib for dental pain. J Clin Pharmacol, 2002. 42(8): p. 912-9.

31. Hersh, E.V., et al., Ibuprofen liquigel for oral surgery pain. Clin The, 2000. 22(11): p. 1306-18.

32. Jamali, F., et al., Human pharmacokinetics of ibuprofen enantiomers following different doses and formulations: intestinal chiral inversion Journal of pharmaceutical sciences, 1992. 81(3): p. 221-225.

33. Shrier, I., R.W. Platt, and R.J. Steele, Mega-trials vs. meta-analysis: Precision vs. heterogeneity? Contemporary clinical trials, 2007. 28(3): p. 324-328.

34. Black, P., et al., A Randomized, Double-Blind, Placebo-Controlled Comparison of the Analgesic Efficacy, Onset of Action, and Tolerability of Ibuprofen Arginate and Ibuprofen in Postoperative Dental Pain. Clinical Therapeutics, 2002. 24(7): p. 1072-89.

35. Li, H., et al., Modeling the Onset and Offset of Dental Pain Relief by Ibuprofen. Journal of Clinical Pharmacology, 2012. 52: p. 89-101.

36. Malmstrom, K., et al., Comparison of Rofecoxib and Celecoxib, Two Cyclooxygenase-2 Inhibitors, in Postoperative Dental Pain:A Randomized, Placeboand Active-Comparator-Controlled Clinical Trial. CLINICALTHERAPEUTICS, 1999. 21(10): p. 1653-63.

37. Brain, P., et al., Onset of Analgesia and Efficacy of Ibuprofen Sodium in Postsurgical Dental Pain: A Randomized, Placebo-controlled Study Versus Standard Ibuprofen. Clin J Pain, 2015. 31(5): p. 44450. 
38. McQuay, H.J., et al., Ibuprofen compared with ibuprofen plus caffeine after third molar surgery. Pain, 1996. 66: p. 247-251.

39. Cheung, R., S. Krishnaswami, and K. Kowalski, Analgesic Efficacy of Celecoxib in Postoperative Oral Surgery Pain: A Single-Dose, Two-Center, Randomized, Double-Blind, Active- and PlaceboControlled Study. Clinical Therapeutics, 2007. 29(Theme Issue): p. 2498-2510.

40. Diamond, S., T.K. Balm, and F.G. Freitag, Ibuprofen plus caffeine in the treatment of tension-type headache. CLINICAL PHARMACOLOGY \& THERAPEUTICS, 2000. 68(3): p. 312-9.

41. Mehlisch, D.R., et al., Comparison of the Analgesic Efficacy of Concurrent Ibuprofen and Paracetamol With Ibuprofen or Paracetamol Alone in the Management of Moderate to Severe Acute Postoperative Dental Pain in Adolescents and Adults: A Randomized, Double-Blind, Placebo-Control. Clinical Therapeutics, 2010. 32(5): p. 882-95.

42. Dionne, R.A. and L. McCullagh, Enhanced analgesia and suppression of plasma beta-endorphin by the S(+)-isomer of ibuprofen. CLINICAL, PHARMACOLOGY \& THERAPEUTICS, 1998. 63(5): p. 694-701.

43. Goldstein, J., et al., Acetaminophen, Aspirin, and Caffeine in Combination Versus Ibuprofen for Acute Migraine: Results From a Multicenter, Double-Blind,
Randomized, Parallel-Group, Single-Dose, PlaceboControlled Study. Headache, 2006. 46: p. 444-453.

44. Morrison, B.W., et al., Analgesic Efficacy of the Cyclooxygenase-2-Specific Inhibitor Rofecoxib in Post-Dental Surgery Pain: A Randomized, Controlled Trial. Clinical Therapeutics, 1999. 21(6): p. 943-53.

45. Packman, E., R. Leyva, and D. Kellstein, Onset of analgesia with ibuprofen sodium in tension-type headache: a randomized trial. Journal of Pharmaceutical Health Care and Sciences, 2015: p. 113.

46. Hill, C.M., et al., Pregabalin in patients with postoperative dental pain. European Journal of Pain, 2001. 5: p. 119-124.

47. Schwartz, J.I., et al., MK-0703 (a Cyclooxygenase-2 inhibitor) in Acute Pain Associated with Dental Surgery: A Randomized, Double-Blind, Placebo- and Active Comparator-Controlled Dose-Ranging Study. American Journal of Therapeutics, 2007. 14: p. 1319.

48. Kleinert, R., et al., Single Dose Analgesic Efficacy of Tapentadol in Postsurgical Dental Pain: The Results of a Randomized, Double-Blind, Placebo-Controlled Study. Anesth Analg, 2008. 107: p. 2048-55.

49. Zelenakas, K., et al., Analgesic efficacy of single oral doses of lumiracoxib and ibuprofen in patients with postoperative dental pain. Int J Clin Pract, 2004. 58(3): p. 251-256. 


\section{Supplementary Material}

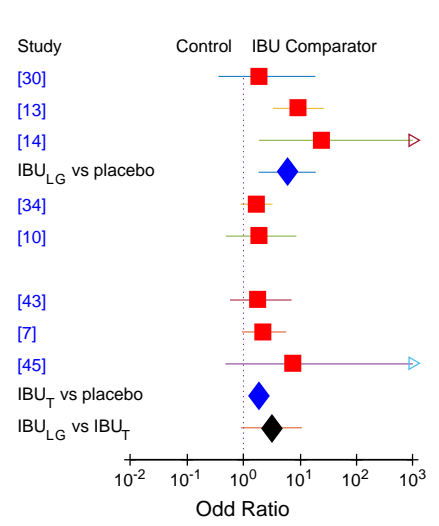

(a) $30 \mathrm{~min}$

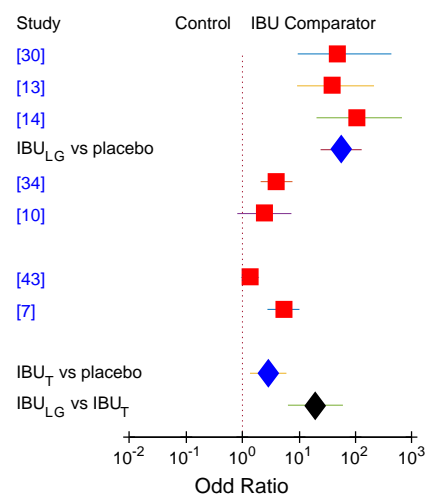

(c) $90 \mathrm{~min}$

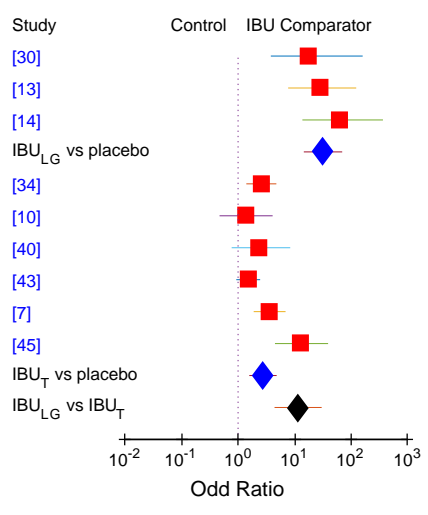

OR[95\% Cl]

$28.13[7.70,123.41]$

$62.83[13.76,367.01]$

$31.88[14.58,69.70]$

$2.58[1.40,4.76]$

$1.38[0.47,4.09]$

2.32[0.77,8.38]

$1.49[0.93,2.46]$

$3.60[1.89,6.93]$

$12.47[4.50,39.24]$

$2.76[1.58,4.82]$

$11.55[4.42,30.19]$ (b) $60 \mathrm{~min}$

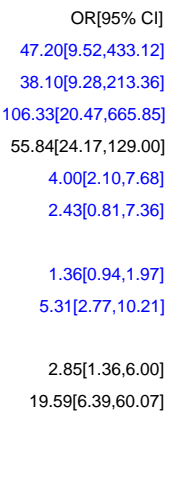

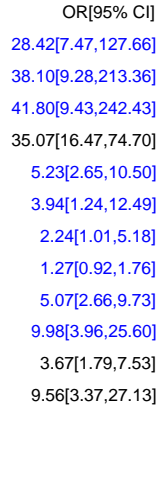

(d) $120 \mathrm{~min}$

Figure 1S. Forest plots of the odd ratios of achieving meaningful pain relief at (a) $30 \mathrm{~min}$, (b) $60 \mathrm{~min}$, (c) $90 \mathrm{~min}$, and (d) 120 post dose
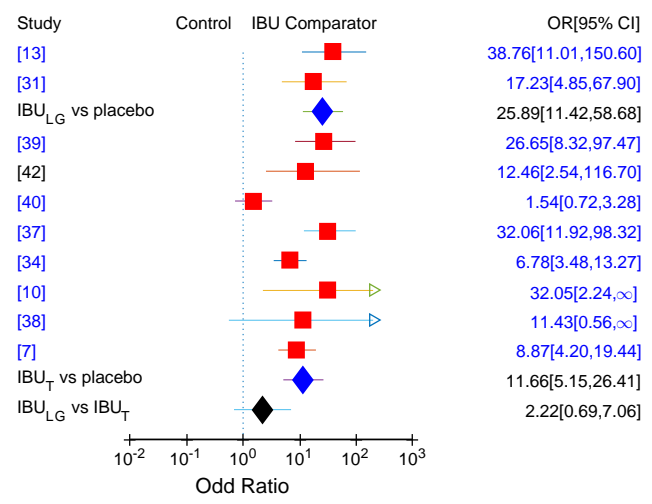

Figure 2S. Forest plot of the odd ratios of achieving at least 50\% paint relief based on TOTPAR 0-6 
Table $1 \mathrm{~S}$.

\begin{tabular}{|c|c|c|c|}
\hline Section/topic & $\#$ & Checklist item & Reported on page \# \\
\hline \multicolumn{4}{|l|}{ TITLE } \\
\hline Title & 1 & Identify the report as a systematic review, meta-analysis, or both. & It is both (page 1) \\
\hline \multicolumn{4}{|l|}{ ABSTRACT } \\
\hline Structured summary & 2 & $\begin{array}{l}\text { Provide a structured summary including, as applicable: background; objectives; data } \\
\text { sources; study eligibility criteria, participants, and interventions; study appraisal and } \\
\text { synthesis methods; results; limitations; conclusions and implications of key findings; } \\
\text { systematic review registration number. }\end{array}$ & Done \\
\hline \multicolumn{4}{|l|}{ INTRODUCTION } \\
\hline Rationale & 3 & Describe the rationale for the review in the context of what is already known. & $\begin{array}{l}\text { Last line of page } 2 \text { and } \\
\text { beginning of page } 3: \\
\text { "However, results ...." }\end{array}$ \\
\hline Objectives & 4 & $\begin{array}{l}\text { Provide an explicit statement of questions being addressed with reference to } \\
\text { participants, interventions, comparisons, outcomes, and study design (PICOS). } \\
\text { We, therefore, attempted to compare the onset of analgesia and efficacy of the } \\
\text { liquigel with solid dosage forms of ibuprofen by undertaking a systematic } \\
\text { review and meta-analysis of all the studies that report onset of analgesia and } \\
\text { efficacy of ibuprofen after administration of these formulations for the treatment } \\
\text { of dental pain or migraine or tension-type headache. }\end{array}$ & $\begin{array}{l}\text { Page 2, paragraph just } \\
\text { before Methods }\end{array}$ \\
\hline \multicolumn{4}{|l|}{ METHODS } \\
\hline Protocol and registration & 5 & $\begin{array}{l}\text { Indicate if a review protocol exists, if and where it can be accessed (e.g., Web address), } \\
\text { and, if available, provide registration information including registration number. }\end{array}$ & $\begin{array}{l}\text { Protocol is with authors. } \\
\text { The study is not } \\
\text { registered }\end{array}$ \\
\hline
\end{tabular}




\begin{tabular}{|c|c|c|c|}
\hline Eligibility criteria & 6 & $\begin{array}{l}\text { Specify study characteristics (e.g., PICOS, length of follow-up) and report } \\
\text { characteristics (e.g., years considered, language, publication status) used as criteria for } \\
\text { eligibility, giving rationale. }\end{array}$ & $\begin{array}{l}\text { Page } 3-4, \text { Methods, } \\
\text { paragraphs 1\&2: "There } \\
\text { was a lack .... hours } \\
\text { post dose" }\end{array}$ \\
\hline Information sources & 7 & $\begin{array}{l}\text { Describe all information sources (e.g., databases with dates of coverage, contact with } \\
\text { study authors to identify additional studies) in the search and date last searched. }\end{array}$ & $\begin{array}{l}\text { Page 3, first paragraph } \\
\text { of Methods (lines 1-3) }\end{array}$ \\
\hline Search & 8 & $\begin{array}{l}\text { Present full electronic search strategy for at least one database, including any limits } \\
\text { used, such that it could be repeated. }\end{array}$ & $\begin{array}{l}\text { Pubmed search terms: } \\
\text { Ibuprofen AND onset } \\
\text { AND study AND (dental } \\
\text { OR "migraine" OR } \\
\text { "tension-type headache" } \\
\text { OR "oral surgery") }\end{array}$ \\
\hline Study selection & 9 & $\begin{array}{l}\text { State the process for selecting studies (i.e., screening, eligibility, included in systematic } \\
\text { review, and, if applicable, included in the meta-analysis). }\end{array}$ & $\begin{array}{l}\text { Page } 3 \text { Presented in } 2^{\text {nd }} \\
\text { paragraph of Methods: } \\
\text { "The review was ..... }\end{array}$ \\
\hline Data collection process & 10 & $\begin{array}{l}\text { Describe method of data extraction from reports (e.g., piloted forms, independently, in } \\
\text { duplicate) and any processes for obtaining and confirming data from investigators. } \\
\text { The screening and eligibility assessment of the reports was carried out } \\
\text { independently by the two authors. }\end{array}$ & $\begin{array}{l}\text { Page 3: First paragraph } \\
\text { of Methods. }\end{array}$ \\
\hline Data items & 11 & $\begin{array}{l}\text { List and define all variables for which data were sought (e.g., PICOS, funding sources) } \\
\text { and any assumptions and simplifications made. }\end{array}$ & $\begin{array}{l}\text { Page } 3 . \text { The } 4^{\text {th }} \text { and } 5^{\text {th }} \\
\text { paragraphs of Methods. } \\
\text { "Two measures ...." }\end{array}$ \\
\hline $\begin{array}{l}\text { Risk of bias in individual } \\
\text { studies }\end{array}$ & 12 & $\begin{array}{l}\text { Describe methods used for assessing risk of bias of individual studies (including } \\
\text { specification of whether this was done at the study or outcome level), and how this } \\
\text { information is to be used in any data synthesis. }\end{array}$ & $\begin{array}{l}\text { Page 3. First paragraph } \\
\text { of Methods, "The } \\
\text { screening ...." } \\
\text { Page 4. Bottom of page. } \\
\text { "Variation among studies } \\
\text { was anticipated, and due } \\
\text { to the heterogeneity ...." }\end{array}$ \\
\hline
\end{tabular}




\begin{tabular}{|c|c|c|c|}
\hline Summary measures & 13 & State the principal summary measures (e.g., risk ratio, difference in means). & $\begin{array}{l}\text { Page } 4,5 \text { :comparing } \\
\text { medians to FPPR and } \\
\text { MPR, OR of achieving } \\
\text { meaningful relief at } 30 \text {, } \\
60,90,120 \text { min post } \\
\text { dose, differences in } \\
\text { mean TOTPAR0- } 6 \text {, and } \\
\text { OR of achieving } 50 \% \text { or } \\
\text { more pain relief based } \\
\text { on TOTPAR. }\end{array}$ \\
\hline Synthesis of results & 14 & $\begin{array}{l}\text { Describe the methods of handling data and combining results of studies, if done, } \\
\left.\text { including measures of consistency (e.g., }\left.\right|^{2}\right) \text { for each meta-analysis. }\end{array}$ & $\begin{array}{l}\text { Pages } 4 \& 5, \text { " } \text { Two } \\
\text { measures .... " }\end{array}$ \\
\hline
\end{tabular}

\begin{tabular}{|c|c|c|c|}
\hline Section/topic & $\#$ & Checklist item & Reported on page \# \\
\hline Risk of bias across studies & 15 & $\begin{array}{l}\text { Specify any assessment of risk of bias that may affect the cumulative evidence (e.g., } \\
\text { publication bias, selective reporting within studies). }\end{array}$ & $\begin{array}{l}\text { No evidence of bias } \\
\text { was found. The } \\
\text { Egger test was } \\
\text { measured but not } \\
\text { reported }\end{array}$ \\
\hline Additional analyses & 16 & $\begin{array}{l}\text { Describe methods of additional analyses (e.g., sensitivity or subgroup analyses, meta- } \\
\text { regression), if done, indicating which were pre-specified. }\end{array}$ & $\begin{array}{l}\text { Subgroup analysis } \\
\text { was used for } \\
\text { specific brand } \\
\text { (Motrin IB) }\end{array}$ \\
\hline \multicolumn{4}{|l|}{ RESULTS } \\
\hline Study selection & 17 & $\begin{array}{l}\text { Give numbers of studies screened, assessed for eligibility, and included in the review, } \\
\text { with reasons for exclusions at each stage, ideally with a flow diagram. }\end{array}$ & $\begin{array}{l}\text { Page 5, paragraphs } \\
1 \& 2 \text { and Figure } 1 .\end{array}$ \\
\hline Study characteristics & 18 & $\begin{array}{l}\text { For each study, present characteristics for which data were extracted (e.g., study size, } \\
\text { PICOS, follow-up period) and provide the citations. }\end{array}$ & Table 1. \\
\hline Risk of bias within studies & 19 & $\begin{array}{l}\text { Present data on risk of bias of each study and, if available, any outcome level } \\
\text { assessment (see item 12). }\end{array}$ & $\begin{array}{l}\text { Not reported as no } \\
\text { bias was found. }\end{array}$ \\
\hline
\end{tabular}




\begin{tabular}{|c|c|c|c|}
\hline & & $\begin{array}{l}\text { Line added to the end of section } 3.2 \text {. } \\
\text { No publication bias was detected by the Egger test except for the OR of IBUT } \\
\text { against placebo at } 2 \mathrm{~h} \text { post-dose (data not reported). }\end{array}$ & \\
\hline Results of individual studies & 20 & $\begin{array}{l}\text { For all outcomes considered (benefits or harms), present, for each study: (a) simple } \\
\text { summary data for each intervention group (b) effect estimates and confidence intervals, } \\
\text { ideally with a forest plot. }\end{array}$ & $\begin{array}{l}\text { Forest plots of the } \\
\text { odd ratios are } \\
\text { added as } \\
\text { supplementary } \\
\text { figures }\end{array}$ \\
\hline Synthesis of results & 21 & $\begin{array}{l}\text { Present results of each meta-analysis done, including confidence intervals and } \\
\text { measures of consistency. }\end{array}$ & Tables 4,6 \\
\hline Risk of bias across studies & 22 & Present results of any assessment of risk of bias across studies (see Item 15). & $\begin{array}{l}\text { Egger test was } \\
\text { used to assess } \\
\text { publication bias and } \\
\text { the results are } \\
\text { described., (data } \\
\text { are not reported) }\end{array}$ \\
\hline Additional analysis & 23 & $\begin{array}{l}\text { Give results of additional analyses, if done (e.g., sensitivity or subgroup analyses, meta- } \\
\text { regression [see Item 16]). }\end{array}$ & $\begin{array}{l}\text { Motrin IB data } \\
\text { given on page } 11 \\
\text { top } 2 \text { lines }\end{array}$ \\
\hline \multicolumn{4}{|l|}{ DISCUSSION } \\
\hline Summary of evidence & 24 & $\begin{array}{l}\text { Summarize the main findings including the strength of evidence for each main outcome; } \\
\text { consider their relevance to key groups (e.g., healthcare providers, users, and policy } \\
\text { makers). }\end{array}$ & $\begin{array}{l}\text { Main findings are } \\
\text { summarized and } \\
\text { incorporated within } \\
\text { the discussion } \\
\text { (pages 8-11) }\end{array}$ \\
\hline Limitations & 25 & $\begin{array}{l}\text { Discuss limitations at study and outcome level (e.g., risk of bias), and at review-level } \\
\text { (e.g., incomplete retrieval of identified research, reporting bias). }\end{array}$ & $\begin{array}{l}\text { Last paragraph on } \\
\text { page } 10: \text { "While } \\
\text { approaches ....." }\end{array}$ \\
\hline Conclusions & 26 & $\begin{array}{l}\text { Provide a general interpretation of the results in the context of other evidence, and } \\
\text { implications for future research. }\end{array}$ & $\begin{array}{l}\text { This is also carried } \\
\text { out in the } \\
\text { discussion (pages } \\
8-11 \text { ) }\end{array}$ \\
\hline
\end{tabular}




\section{FUNDING}

Funding

Describe sources of funding for the systematic review and other support (e.g., supply of data); role of funders for the systematic review.

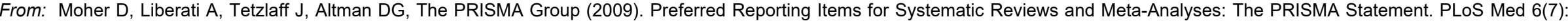
e1000097. doi:10.1371/journal.pmed1000097

For more information, visit: www.prisma-statement.org. 